\section{NEUES AUS DER INDUSTRIE}

\section{Erste Schmelze mit der neuen VAR Anlage bei Ruspolymet}

Nach einer erfolgreichen Inbetriebnahme der VIM und ESU Anlage in den letzten Monaten konzentrieren sich INTECOs Experten im Moment auf die Kommissionierung des 6t VAR Ofens. Mitte November konnte nun in enger Zusammenarbeit mit dem Team von Ruspolymet die erste Schmelze erfolgreich durchgeführt werden.

Der VAR Ofen wird das neue Sonderstahl-/Umschmelzwerk bei Ruspolymet in Kulebaki komplettieren und beinhaltet selbstverständlich die neueste Technologie im Gebiet des Vakuumlichtbogenumschmelzens, wie z. B. präzise Tropfenregelung, niedrigste Vakuum-Level sowie ein Heliumkühlsystem für besten Wärmeübergang vom Block in die Kokille.

Die drei Öfen sind perfekt aufeinander abgestimmt, um Elektroden aus dem VIM Ofen entweder mit der ESU Anlage oder dem VAR Ofen oder sogar anhand eines doppelten Schmelzprozesses für höchste Anforderungen umzuschmelzen.

\section{Erste Schmelze mit der neuen ESU Anlage bei Uddeholm}

Nur unglaubliche sieben Monate nach der Auftragserteilung wurde im November die erste Schmelze mit der zweiten neuen ESU Anlage bei Uddeholm durchgeführt.

Diese Anlage ist eine identische Kopie der ersten INTECO ESU Anlage, welche im April dieses Jahres beim weltgrößten Werkzeugstahl-Hersteller in Betrieb gegangen ist.

Es handelt sich um eine Standtiegelanlage, welche Blöcke mit einer Größe von ungefähr 30t und einem maximalen Durchmesser von $1250 \mathrm{~mm}$ unter Schutzgasbetrieb in einem Druckbereich von bis zu 3 bar produzieren kann.

Das INTECO Team erwartet die erfolgreiche Absolvierung aller Abnahmeschmelzen vor Weihnachten 2015.

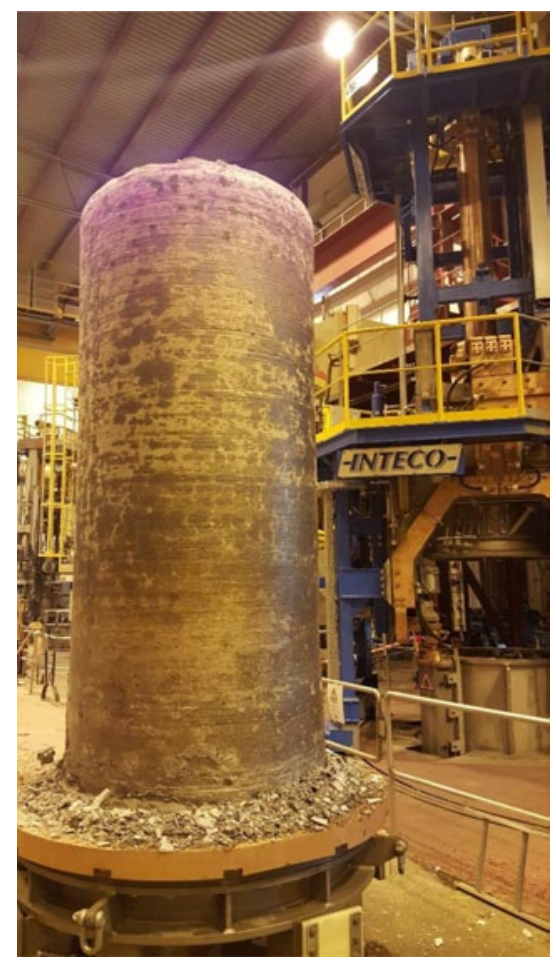

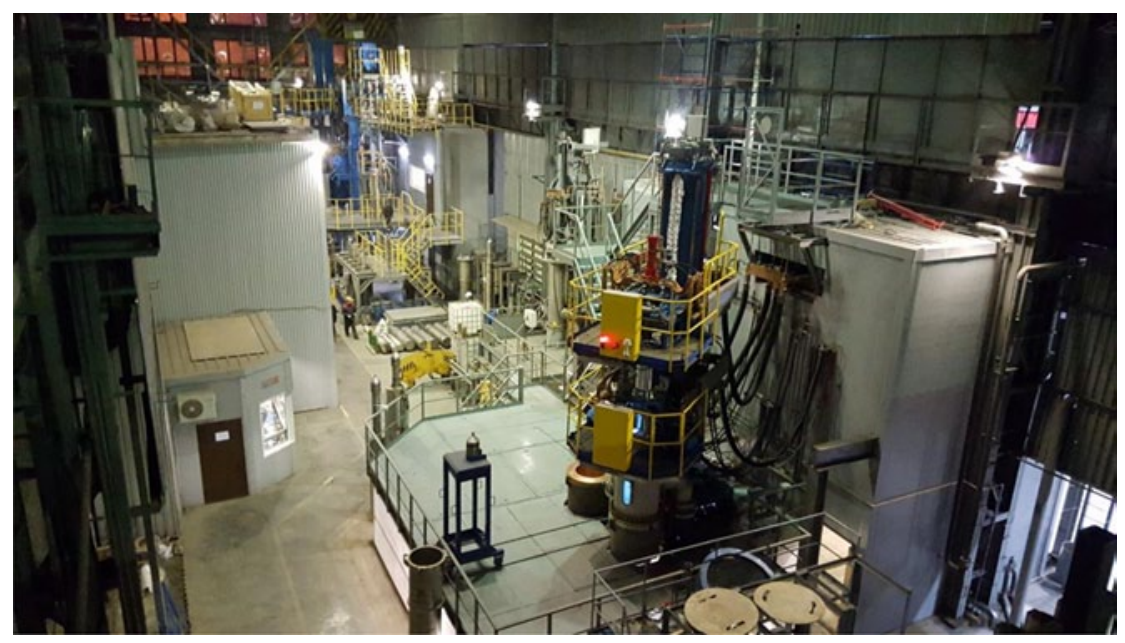

